\title{
Mulheres na maturidade e queixa depressiva: compartilhando histórias, revendo desafios
}

\author{
Isalena Santos Carvalho ${ }^{1}$ \\ Vera Lúcia Decnop Coelho
}

\begin{abstract}
Resumo
$\mathrm{Na}$ literatura, a maturidade feminina tende a ser caracterizada pela menopausa, saída dos filhos de casa, cuidado e/ou perda dos pais idosos e questionamento sobre as escolhas de vida. Outra questão associada é a possibilidade de ocorrência de sintomatologia depressiva. Nessa perspectiva, o presente trabalho buscou identificar eventos da maturidade possivelmente relacionados à depressão feminina. Nove mulheres com diagnóstico de depressão, atendidas num hospital público de Brasília, participaram de uma intervenção psicológica grupal. A análise dos encontros sugere que perdas associadas ao seu envelhecimento, como a ocorrência de limitações físicas, modificações na autoimagem e nas relações interpessoais específicas da maturidade, bem como o receio de dependência familiar futura contribuíram para a sintomatologia em questão. A dificuldade de elaboração de novos projetos de vida, com a depreciação do valor pessoal, foi um outro fator possivelmente relacionado. Cabe avaliar desafios enfrentados pelas mulheres na maturidade para a compreensão da queixa depressiva e desenvolvimento de propostas de intervenção. Palavras-chave: Maturidade; Depressão; Menopausa; Envelhecimento; Grupo.
\end{abstract}

\section{Women in maturity and depressive complaint: sharing histories, reviewing challenges}

\begin{abstract}
In literature, feminine maturity tends to be characterized by menopause, departure of children from home, care or loss of aged parents and questioning about life choices. Another question associated is the possibility of depressive symptoms occurrence. In that perspective, this article aims at identifying events of maturity possibly related to feminine depression. Nine women with depression diagnosis, attended in a public hospital in Brasília, took part in a group of psychological intervention. The analysis of the encounters suggests that losses associated to their aging process, such as occurrence of physical limitations, modifications in their auto-image and in the interpersonal relations specific of maturity, as well as the fear of future familiar dependency, have contributed to the symptoms related above. The difficulty of elaborating new life projects, with depreciation of the personal value was another factor possibly related. It is necessary to evaluate challenges faced by women in maturity for an understanding of the depressive complaint and the development of intervention proposals.
\end{abstract}

Keywords: Maturity; Depression; Menopause; Aging; Group.

\section{Introdução}

Envelhecer implica enfrentar uma série de perdas reais e simbólicas. A mulher, com o término de sua capacidade reprodutiva, configurada pela menopausa, tende a se perceber entre dois momentos socialmente antagônicos: a juventude e a velhice. No entanto, se a jovem é exaltada, a mulher idosa, parafraseando Simone de Beauvoir, é sempre a outra. Pode-se perceber que mitos e preconceitos sobre as mudanças enfrentadas pela mulher que envelhece continuam presentes em nossa sociedade (Ciornai, 1999; Ramos, 1998). No Brasil, parece ser precária a quantidade de serviços na rede pública de saúde e de estudos destinados à menopausa e à maturidade, o que contribui para uma visão estereotipada das dificuldades que as mulheres enfrentam nessa etapa da vida (Diniz \& Coelho, 2003; Mori, 2002). Isto dificulta uma melhor compreensão de fatores que podem levá-las a adoecer e o incentivo ao desenvolvimento de mais espaços de atendimento condizentes com suas demandas.

Em revisão de estudos sobre a depressão em mulheres na maturidade, observa-se certa ênfase na menopausa como fator propiciador. A partir de Kraepelin, foi apontada uma condição psicopatológica associada ao período da menopausa, então denominada Melancolia Involutiva. De acordo com Appolinário (2001), até a década de 1970, alguns autores - baseados

${ }^{1}$ Endereço para correspondência:

Rua Perdizes - Cond. Versalhes - apto. 302 - A, Renascença - II - 65075-340 - São Luís-MA

Fone: (98) 3227-8341 - Fax: (098) 3214-3060

E-mail: isalenasc@unb.br 
em estudos que apresentavam problemas metodológicos - defendiam a idéia de uma entidade psiquiátrica que seria específica da menopausa.

A Melancolia Involutiva seria caracterizada por depressão, ansiedade, agitação e insônia severas, sendo que sentimentos de culpa e somatizações estariam freqüentemente presentes, podendo atingir graves proporções. Com o surgimento dos primeiros estudos epidemiológicos, utilizando a técnica de corte transversal e, mais adiante, a técnica longitudinal, não foi confirmado o maior risco de morbidade psiquiátrica na menopausa. Nas últimas décadas, em lugar da antiga Melancolia Involutiva, considera-se que a mulher na maturidade pode apresentar a Síndrome do Climatério (Appolinário, 2001).

Tende-se a considerar que a depressão feminina na maturidade, durante e após a menopausa, seja decorrente de diversos fatores, como doenças físicas (exemplo: hipotiroidismo) e condições estressantes psicológicas, sociais e culturais (Appolinário, 2001). Há ainda muita polêmica sobre a relação entre depressão e menopausa, de modo que se faz necessário que mais estudos epidemiológicos e clínicos esclareçam essa relação. Assim, é preciso cautela ao se considerar a redução estrogênica como um evento responsável pela ocorrência de um conjunto de doenças, como a depressão. A mulher pode temer esta fase de seu ciclo vital, julgando que, além das mudanças em seu corpo, haverá mudanças negativas em sua personalidade e relações interpessoais. Sem a informação necessária, é provável que receie questionar essas mudanças.

Dados do "Projeto de Apoio e Valorização da Mulher" (Diniz \& Coelho, 2003) demonstram que uma das queixas recorrentes dos grupos de mulheres na maturidade é a depressão. Segundo as autoras, são diversas as queixas relatadas no primeiro encontro, envolvendo desde problemas físicos a dificuldades emocionais e sociais. Como seu estudo é realizado num serviço público de saúde, muitas vezes as mulheres buscam nos encontros consultas médicas, medicação ou mesmo alívio para as dificuldades pessoais e familiares. Contudo, no decorrer da atividade em grupo, as participantes percebem que os encontros "permitem trazer queixas de uma outra ordem, outras dores, que na maioria das vezes não têm espaço nas consultas médicas e no dia-a-dia" (p. 102).

É nesse contexto que se justifica o presente estudo, parte de uma pesquisa realizada com mulheres na maturidade, com diagnóstico de depressão e sob acompanhamento psiquiátrico. Busca-se discutir, com base no relato de mulheres que participaram de uma intervenção psicológica grupal, eventos que tendem a ocorrer nessa fase e que podem contribuir para a cons- tituição de sintomas depressivos. Inicialmente, são abordados de forma sucinta alguns aspectos da maturidade feminina; em seguida, apresenta-se a pesquisa desenvolvida num hospital público do Distrito Federal.

\section{A menopausa}

Ainda é comum se detectar, na mídia e na sociedade como um todo, uma discriminação implícita pela propagação de uma visão negativa da mulher que envelhece. Essa visão pode ser reforçada pelo estímulo ao emprego da Terapia de Reposição Hormonal. No entanto, a reposição não é questão consensual na Medicina. É um tema polêmico na área médica e em outras áreas da saúde, em face dos possíveis riscos associados ao seu uso (Mori, 2002; Ramos, 1998).

Ramos (1998) afirmou que muitos sintomas presentes nessa etapa da vida feminina são atribuídos indevidamente à menopausa, dentre eles os depressivos. A autora apontou que apenas irregularidades menstruais, ondas de calor e secura vaginal podem ser, de fato, associados a esse fenômeno. Em concordância com Ramos e outros autores que não restringem a menopausa a um evento biológico, consideramos que, ao término da capacidade reprodutiva, são conferidos os mais diversos significados pela mulher, pela família e pela sociedade. Não é apenas a maternidade, vista como um destino feminino por natureza, que se coloca em questão com a chegada da menopausa, são todos os papéis culturalmente atribuídos à mulher. Desse modo, à redução hormonal somam-se mudanças psicossociais peculiares à maturidade, os quais tendem a trazer uma série de implicações para a auto-imagem da mulher que envelhece.

\section{Eventos psicossociais associados à maturidade}

Tradicionalmente, as mulheres sempre desempenharam um papel central nas famílias, mas a idéia de que têm uma vida à parte de seus papéis como esposa $\mathrm{e}$ mãe é algo relativamente recente e ainda não amplamente aceito em nossa sociedade. Quando se rebelam contra a responsabilidade total pelos vínculos familiares e pela conservação das tradições e rituais, podem se sentir culpadas por não mais exercerem essas funções. Podem sentir ainda que a solidariedade familiar está sucumbindo e que a responsabilidade por isso pertence unicamente a elas (Coelho \& Diniz, 2005; McGoldrick, 1995).

Mulheres que nunca trabalharam fora de casa podem se sentir defasadas no que se refere às capacidades necessárias para lidar com o mundo externo, caso decidam ou necessitem enfrentar o mercado de trabalho. No momento em que os filhos não dependem mais delas como antes e quando estão começando a ser defi- 
nidas como "velhas demais" (McGoldrick, 1995, p. 50), é que precisam aventurar-se lá fora. A organização do trabalho remunerado ainda "não reconhece seus esforços de maneira proporcional às suas contribuições. $E$ as mulheres, tipicamente, não foram socializadas para esperar ou exigir o reconhecimento que merecem" (McGoldrick, 1995, p. 51). Contudo, muitas mulheres, após a dificuldade inicial diante do novo contexto, adquirem confiança e prazer com sua nova independência. Podem descobrir em si competências que até então não puderam desenvolver em razão do tempo dedicado aos filhos ou a outras atividades, com a valorização de seu potencial. Desse modo, percebe-se que as mulheres tendem a enfrentar muitos desafios na maturidade. $\mathrm{Na}$ literatura específica, destacam-se os seguintes eventos:

a) Cuidado ou perda dos pais - à medida que os pais envelhecem, a mulher freqüentemente passa a cuidar deles, sobretudo quando apresentam enfermidades que limitam a sua autonomia. Muitas mulheres entre 55 e 59 anos de idade cuidam, em casa, de um parente idoso. Essa tendência foi recentemente confirmada por Coelho e Diniz (2005), quando discutem a assistência familiar à pessoa idosa com demência. Esposas, filhas e noras permanecem como as principais cuidadoras. $\mathrm{O}$ cuidado de pais idosos pode trazer conflitos familiares para a mulher, fazendo com que se sinta dividida entre sua atual família, seus pais e suas necessidades pessoais.

Como cada vez mais as mulheres ingressam no mercado de trabalho, cuidar do parente enfermo pode aumentar suas atribuições cotidianas para as quais não encontra suporte familiar (Coelho \& Diniz, 2005). A cobrança para que zele pelos familiares pode levá-la a se considerar egoísta por buscar uma auto-realização. A morte dos pais também pode ocorrer nesse período, lembrando-a de sua própria finitude.

b) Divórcio ou viuvez - além das próprias mudanças biológicas e psicossociais que a mulher experiencia, seu parceiro de mesma faixa etária provavelmente enfrenta dificuldades similares. Lidar com essas mudanças pessoais e, conseqüentemente conjugais, pode ser penoso, em especial para aqueles casais que, ao longo do relacionamento, não estabeleceram uma comunicação mais íntima.

A mulher que desenvolveu uma identidade primariamente baseada na dedicação às necessidades do companheiro estará particularmente vulnerável ao divórcio durante esta fase. Com o término da relação, ela poderá ter seu poder aquisitivo reduzido na partilha dos bens do casal. Geralmente, é a mulher que diminui significativamente de renda quando o casal se separa (McGoldrick, 1995). Na viuvez, pode apegar-se aos filhos e aos netos para suprir a ausência do companheiro. Como ocorre no divórcio, seu poder aquisitivo também tende a diminuir.

c) Trabalho / aposentadoria - quando a mulher não tem renda própria, fruto de trabalho remunerado, é comum sentir-se em desvantagem por depender do marido e/ou dos filhos e, assim, com pouca autoridade nas decisões familiares e pessoais. A mulher que era dona-de-casa em tempo integral, ao procurar trabalho, poderá igualmente se sentir discriminada por apresentar poucas habilitações. Por outro lado, as que trabalhavam fora podem apresentar conflitos no momento da aposentadoria, pois esta determina com freqüência um declínio financeiro, além da perda de identidade profissional.

d) Crescimento dos filhos: ninho vazio? - $\mathrm{Na}$ literatura sobre maturidade, é comum a referência à "Síndrome do ninho vazio" para caracterizar o processo enfrentado pelas mulheres diante da percepção do crescimento dos filhos. Tal expressão precisa ser questionada, pois o termo síndrome, enquanto um conjunto de sinais e sintomas, remete a uma concepção de doença que não nos auxilia a compreender o necessário trabalho de luto que realizam.

As mulheres que não tinham uma atividade profissional fora do contexto familiar podem ser as mais atingidas nesse aspecto. Ao reconhecerem que seus filhos estão saindo de casa para seguir seus próprios caminhos, elas podem se ver estagnadas no papel familiar materno (McGoldrick, 1995). A convivência com filhos adolescentes e adultos jovens traz novos desafios. Além disso, a gravidez não esperada das filhas ou namoradas dos filhos pode transportar a mulher mais cedo do que talvez desejasse ao status de avó. Isto contribui para o aumento de suas responsabilidades, principalmente se os netos ficarem sob sua guarda ou cuidado.

Em conseqüência dessas mudanças, a mulher tende a realizar uma revisão de sua vida e do papel que passa a ocupar na dinâmica familiar e em suas demais relações interpessoais. Ela poderá se questionar sobre suas escolhas, considerando-as desfavoráveis a si e a sua família, depreciando seu valor pessoal. A menopausa, o crescimento dos filhos, a sobrecarga em suas responsabilidades quando necessita cuidar de seus pais e a aposentadoria são eventos que lhe indicam as perdas inevitáveis da maturidade. As perdas refletem a proximidade de sua velhice, um tempo que exige outras elaborações (Ciornai, 1999; Py, 2004). Com a apresentação desse suporte teórico, cabe agora discutir como algumas mulheres falam de possíveis eventos da maturidade que associam à depressão. 


\section{Método}

\section{Participantes}

Participaram do estudo nove mulheres entre 40 e 60 anos, de baixa renda, em atendimento psiquiátrico ambulatorial com diagnóstico de depressão, segundo os critérios da CID-10 (OMS, 1994). Os fatores de exclusão ao estudo foram: suspeita de retardo mental, psicose e quadros demenciais.

\section{Local do estudo}

A pesquisa foi realizada na cidade de Brasília com usuárias de um Ambulatório de Psiquiatria de um hospital da rede pública de saúde do Distrito Federal. O projeto de pesquisa foi submetido à direção da instituição e, após a sua autorização, foi encaminhado ao Comitê de Ética da Secretaria de Estado da Saúde do Distrito Federal. Os dados foram coletados entre março e setembro de 2003.

\section{Estratégias de investigação e procedimentos}

Solicitou-se o encaminhamento de usuárias que atendessem aos critérios do estudo aos profissionais do Ambulatório de Psiquiatria. A partir do encaminhamento, que ocorria após a consulta psiquiátrica, eram esclarecidos a cada participante os objetivos e as etapas da pesquisa, com a leitura do Termo de Consentimento Livre e Esclarecido. No mesmo dia, em geral, era aplicado o Inventário Beck de Depressão - BDI (Cunha, 2001), e realizada entrevista semi-estruturada individual. No total, foram entrevistadas 18 mulheres e, dessas, apenas nove participaram da intervenção grupal. As demais não se dispuseram a continuar na pesquisa. Houve ainda dúvida quanto ao diagnóstico de depressão de uma delas, motivo pelo qual se optou por sua não inclusão na proposta grupal. Com a conclusão das entrevistas, foram iniciados os encontros em grupo.

A metodologia do trabalho foi fundamentada no "Projeto de Apoio e Valorização da Mulher", desenvolvido por pesquisadoras do Laboratório de Psicoterapia e Psicodiagnóstico do Departamento de Psicologia Clínica da Universidade de Brasília (UnB). A proposta do Projeto consiste em pesquisa e intervenção psicológica com grupos de mulheres na maturidade, com vistas à prevenção e promoção da saúde mental (Diniz \& Coelho, 2003).

Foram realizados sete encontros quinzenais. $\mathrm{O}$ primeiro foi reservado para a apresentação de cada participante, levantamento de expectativas e constituição do clima grupal. No segundo, buscou-se identificar os temas de maior interesse das mulheres, os quais foram debatidos ao longo do trabalho. Também foram abordados temas sugeridos pelas coordenadoras do grupo.
No terceiro encontro, foi proposta a questão "O que é ser mulher?" para o debate. Na quarta e quinta reuniões, foi abordado o tema "Depressão". No sexto encontro, discutiu-se o tema "Perdas ao longo da vida". No último, foi realizada uma avaliação da experiência grupal pelas participantes.

Os encontros foram transcritos e analisados segundo a proposta hermenêutico-dialética (Minayo, 1993). Reunindo as entrevistas transcritas, constituiu-se o corpus da pesquisa com a leitura exaustiva dos textos. Para fins do presente estudo, a análise dos encontros grupais focalizou a vivência da maturidade e sua relação com a queixa depressiva.

\section{Resultados e discussão}

Dois temas se destacaram em relação ao tema maturidade e queixa depressiva no depoimento das mulheres que participaram da proposta grupal: "As implicações do envelhecimento sobre o corpo" e "Mudanças biopsicossociais - receios e desafios". Esses temas são a seguir discutidos e ilustrados com algumas falas das participantes. Ressalta-se que os nomes utilizados para a identificação das mulheres são fictícios.

\section{As implicacões do envelhecimento sobre o corpo}

É importante avaliar como as condições socioeconômicas podem afetar a saúde das mulheres na maturidade. A mulher apresenta queixas clínicas marcadas pelo acesso ou dificuldade de acesso a serviços necessários à melhoria de sua qualidade de vida segundo a classe social na qual está inserida. Nesse sentido, Miranda (1996), ao buscar enfocar o(s) significado(s) atribuído(s) à menopausa por mulheres da favela Real Parque, em São Paulo, identificou alguns temas mais freqüentes nos depoimentos: corpo (como lugar de sintomas e perda da força de trabalho), atividades e emoções (destaque aos papéis tradicionalmente femininos, em primeiro lugar, e, em segundo, falta de perspectiva profissional), sexualidade (diminuição da libido, por causa de relacionamento insatisfatório) e ambiente de moradia (medo e preocupação). A pesquisadora concluiu que a menopausa em si era pouco significativa para as mulheres faveladas. Questões referentes à habitação e renda adquiriram mais sentido em suas vidas com a possibilidade de limitações físicas favorecidas pelo processo de envelhecimento.

Como o grupo analisado no presente estudo é formado por mulheres de baixo poder aquisitivo, estas precisaram ajudar na renda familiar, logo que adquiriram habilidades necessárias na infância. Contudo, com o envelhecimento, sentem que o corpo, principal 
instrumento de trabalho, muitas vezes não corresponde mais ao que era antes. Diante da possibilidade da ausência do trabalho, dentro e fora do contexto familiar, sua noção de valor pessoal fica prejudicada, o que contribui para seu adoecimento.

Ao contrário do que as pesquisas indicam sobre possíveis efeitos da aposentadoria nos homens (McGoldrick, 1995; Miranda, 1996), esta não foi identificada como um evento propiciador da queixa depressiva nas participantes. A aposentadoria não faz parte da vida da dona-de-casa. Com uma rotina intensa de atividades no ambiente doméstico, precisam continuar trabalhando para suprir suas necessidades e as dos familiares. Contudo, com as transformações perce-bidas no corpo, relacionam a redução da capacidade física, com repercussões em suas oportunidades de sustento e autonomia, à ocorrência de sintomas depressivos.

Goldfarb (1998) indicou que, muitas vezes, com a aproximação da velhice, o que se torna mais preocupante não é o aspecto estético da deterioração no corpo, mas a possibilidade de dependência pela perda de força física. Com a ausência do trabalho, que pode significar uma futura necessidade de demanda financeira aos familiares, as mulheres temem se sentir como um "peso" - conforme as palavras de Rute e Isaura, participantes do grupo.

Essas mulheres percebem, assim, que estão num outro momento de vida quando o corpo apresenta sinais de desgaste. Este tende a ser descrito como um objeto estranho, que se torna alvo de desconfiança, pois pode vir a falhar. Magnólia, por exemplo, antes de apresentar artrose nas mãos, razão pela qual deixou de trabalhar, considerava que "não tinha problema algum". Ao sentir que não tinha mais controle sobre os próprios movimentos, não sabe mais o que esperar do próprio corpo. Este, assim, deixa de ser visto como um aliado, quando é preciso controlá-lo cuidadosamente para que continue correspondendo às expectativas e necessidades.

A independência econômica das mulheres, que têm profundas implicações nas estruturas familiares tradicionais, torna-se fundamental nesse momento como fator de proteção às possíveis demandas que venham a ter, com a aproximação de sua velhice. A dependência, ao criar um desequilíbrio de poder nas relações familiares, tende a trazer sérios prejuízos à mulher que envelhece. Em paralelo, o receio de apresentarem doenças associadas ao envelhecimento foi identificado igualmente como uma situação que favorece a constituição de sintomas depressivos, como nos indica Graça:

Não sei se é porque vai chegando a idade, a saúde também vai diminuindo, né? É problema de hipertenso,

Psico-USF, v. 11, n. 1, p. 113-122, jan./jun. 2006 diabetes, coluna... Então a gente vai ficando assim... É menos... menos força pro trabalho, né? E saber que tem que trabalhar ainda, que eu não tenho filhos nem marido, né? Eu sou solteira. Então eu fico não querendo depender de irmão, né? Então é isso aí que me faz... que eu sinto essa depressão, essa ruindade.

Graça e algumas participantes, ao realizarem um processo de revisão de vida, demonstraram um sentimento de estagnação. A dependência é considerada como uma confirmação de que suas realizações não tiveram relevância. Se tivessem concluído os estudos, se não tivessem deixado o emprego por causa de maridos e filhos, dentre outros eventos, talvez tivessem uma situação econômica mais favorável. Com o envelhecimento, sentem que suas possibilidades de acesso a uma melhor qualidade de vida se tornam mais escassas (Miranda, 1996).

Algumas se queixam da falta de energia para retomarem os estudos, sentindo-se em desvantagem pela pouca instrução para acompanhar o desenvolvimento tecnológico. A carência de habilidade técnica diante das crescentes exigências do mercado de trabalho contribui para o aumento do receio relacionado à proximidade da velhice. Somado a este fator, a visão negativa acerca do envelhecimento não favorece a possibilidade de novas conquistas profissionais e de estabilidade financeira, o que se pode observar no relato de Vilma quando descreve o modo como sua "patrod" a trata:

\section{Ela tava me achando incapaz de conseguir um outro serviço, é isso. Ela acha que na minha idade, que sou incapaz... Poxa, eu não tenho leitura, nem... Aliás, assim, não dá pra mim arrumar um serviço numa coisa que seja pesada, se for pra mim arrumar um serviço vai ser nas casa, de doméstica mesmo, mas ela pensa que eu não tenho essa capacidade de sair por ai a trabalhar nas casas.}

Ser mulher, ser pobre e ser velha, como é exemplificado por Vilma, são fatores que se somam, refletindo uma série de preconceitos presentes em sua realidade de vida. $\mathrm{O}$ relato acima nos indica, assim, que o processo de envelhecimento não é apenas determinado pela cronologia e aspectos biológicos, mas igualmente pela condição socioeconômica e pela singularidade das histórias de vida (Sánchez \& Roel, 2001). Goldfarb (1998) apontou que a violência exercida por intermédio do discurso de exaltação da juventude e da produtividade propõe um modelo que desvaloriza o processo de envelhecimento, como se o sujeito que envelhece não pudesse mais desejar, nem ter 
acesso aos seus direitos. A falta de um reconhecimento social e de um lugar simbólico para o envelhecimento e para a velhice resulta numa falta de investimento do ambiente em direção a esse sujeito e vice-versa. Muitas vezes, a resposta a esse processo é identificada como depressão.

A consciência do próprio envelhecimento físico implica a perda da ilusão da potência. Quando o corpo mostra os sinais do avançar do tempo, algumas participantes do grupo percebem que seu principal projeto em longo prazo agora é se preparar para uma velhice digna. A ansiedade que se desenvolve acerca de limitações físicas também demonstra que podem vir a falhar no exercício das atividades domésticas. Se o corpo não serve mais como instrumento de trabalho, há um questionamento acerca do lugar da mulher no contexto familiar e de uma possível desvalorização que venha a sofrer. Com o término da capacidade reprodutiva, esse questionamento tende a se acentuar.

\section{Mudanças biopsicossociais: receios e desafios}

A menopausa foi igualmente retratada pelas participantes como um evento que pode favorecer a ocorrência de sintomas depressivos. Se, antes da cessação da menstruação, as participantes se consideravam como mulheres ágeis e decididas "mulher nordestina é mulher forte", como nos diz Dora - o corpo que não mais reproduz confirma as mudanças no papel social decorrentes do processo de envelhecimento.

Com o aumento da expectativa de vida, as transformações na sociedade e no âmbito familiar trouxeram maior visibilidade ao envelhecimento feminino. Entretanto, a valorização dessa etapa de vida ainda permanece em desproporção. $\mathrm{Na}$ maturidade, a mulher se defronta radicalmente com a necessidade de elaboração de projetos mais realistas e com os efeitos que isso produz na sua relação com o passado - quando acreditava ter ainda muito tempo para modificar suas escolhas. A constatação pode se materializar nas mais diversas perdas, como a menopausa, que evidencia o término dos ciclos menstruais e da capacidade reprodutiva, indicadores de sua juventude. A modificação dos atributos e emblemas da beleza da juventude podem levar a mulher a uma experiência de luto, experiência essa significativamente descrita por Rute na analogia que realiza sobre o ciclo vital feminino:

Pra mim, mulher na minha cabeça é assim: quando vocêe é criança, é igual um botão, todo mundo ali acaricia, todo mundo the tem aquele... the paparica. Ai você vai crescendo, aí vai vendo as desilusões, vai começando os espinhozinhos. Primeiro espinho, que vem, que en comparo, é a menstruação. Porque tudo é a mulher. (...) Quer dizer, a isso, eu comparo assim... Ai a mulher vem, ai já é um sofrimento. Ai, depois você vai à luta, você tem que trabalhar, estudar pra se manter, depois vem um homem, você se apaixona, é aquele amor, aquela mil maravilha. Ai vão casar. Aí, quando casa, ai lá vem filho, lá vem problema, marido bebe, marido chega em casa tarde. Os filhos quando é pequeno é tudo ali agarrado com a gente. Quando vão chegando a uma certa idade vão se libertando, querendo já sair sozinho... Ai quando chega a menopausa, ai a mulher se desmantela toda. (...) Assim, a gente começa como um botãozinho de rosa... ai depois vai despetalando, uma a... Eu digo a menopausa desmantela no sentido que eu digo, assim, de vir tanta coisa que aparece que você antes não tinha: depressão, vem a falta do apetite sexual. Tem dia que se eu pudesse... Eu deito na cama igual à Pantera Cor-deRosa: de ponta de pé, que é pro marido não acordar. (...) Ai, é uma coisa, e ele é o marido que tá na... que tá no auge, né? Que tá com cinqüenta e seis anos.

O crescimento dos filhos e sua saída de casa sinalizam para Rute que seu papel de cuidar precisa ser revisto. Ao ocupar um outro lugar no mundo dos filhos, já adultos e com interesses próprios, não reconhece mais sua importância na dinâmica familiar. Acostumada com a presença deles, Rute descreveu um estranhamento ante o silêncio que se instalou em sua casa. Durante anos, seu marido saía muito para se divertir, deixando-a sozinha com as crianças. Quando "finalmente" o marido quis convidá-la para acompanhálo em seus passeios, não sentia mais prazer em sair de casa, preferindo isolar-se.

Da menarca ao casamento, do crescimento dos filhos à menopausa, eventos que se entrelaçam, marcando o término de várias etapas do ciclo vital e a revisão de sua história. Pode-se inferir acerca da etapa descrita por Rute, quando "a mulher se desmantela toda", a expressão de diversas perdas vivenciadas no envelhecimento feminino: da juventude, do crescimento dos filhos e da auto-imagem (Ciornai, 1999; Py, 2004).

Nas metáforas presentes no discurso dessa participante, a vida da mulher é retratada como cheia de espinhos, que representam os sofrimentos enfrentados. O despreparo que sentiu na vivência desses marcos da vida se repete agora na menopausa, percebida como outro espinho, mais um sofrimento. Em sua fala, a menopausa consiste em "apenas" mais uma etapa desconhecida pela mulher acerca de seu próprio corpo e sexualidade. A menopausa, mesmo com toda a divulgação realizada atualmente (Ciornai, 1999; Mori, 2002; Ramos, 1998), tende a causar receio, pois, se quando jovem a mulher se percebia como um botão e, 
mais tarde, como uma rosa, ao envelhecer não sabe mais o que pode ser. Ao perder a capacidade reprodutiva, aquilo que é socialmente percebido como o que a torna mulher, Rute sente que perdeu sua feminilidade.

Com a perda da juventude, Rute - assim como muitas outras mulheres - não deseja "murchar". Reconhece que a sociedade é, por vezes, severa com as mulheres quando envelhecem. Teme ficar sem valor, agora que os filhos cresceram e que o marido continua no "auge". A perda do status da juventude, marcada pela menopausa, representa um processo estranho sobre o qual silencia qualquer possibilidade de questionamento. Assim como não teve com quem compartilhar suas dúvidas sobre as etapas anteriores (menarca, gestação, parto etc.), Rute acredita que esta situação se repete. Sentindo-se só, descreve a menopausa com apreensão. Contudo, ela não está só. Outras também receiam as transformações que têm lugar nesse período de vida.

É possível considerar que a visão da menopausa enquanto um desastre está sedimentada num contexto de desvalorização da mulher (Ciornai, 1999). A manutenção da visão da procriação como a principal finalidade em sua vida restringe todas as possibilidades de criação de novos projetos para além da maternidade. Desse modo, a mulher pode acreditar que o reconhecimento social depende da sua capacidade de gerar e criar filhos.

Quando as demais participantes do grupo escutaram o depoimento de Rute, criticaram seu modo de descrever a mulher e a menopausa. "Ser mulher é isso aî?", questionou Leila. Embora não concordassem com Rute, algumas também expressaram dúvidas acerca do que pode ocorrer na menopausa. Essas dúvidas refletem o receio a respeito do impacto de seu envelhecimento na família. Como serão tratadas em sua velhice? Serão incentivadas a construir novos projetos de vida? Norma, por exemplo, sente-se estagnada por supor que não tem mais nada a criar:

(...) mas eu acredito que tem dois grupos de mulher: tem um grupo de mulher independente, estudada, é... chique. Né? E tem um grupo de mulher, assim como sou eu, insegura, mas porém, assim... Nasci pra ser mãe. (...) E term um grupo de mulher, que é aquelas que... que estuda, que tem mais conhecimento, que com certeza tem outro ponto de vista. Que não é tão insegura, às vezes não é tão... dedicada: casa, marido, filhos. Essas mulheres, eu acredito que seja mais saudável, né? Do que esse grupo que nasceu pra ser dona de casa, mãe, é... mulher. E essa eu acredito que seja aquela que sofre mais, que, que tem esses mesmo problemas nossos aqui. (...) elas vêm em dois tipo, aquela que é totalmente independente, que não se liga

Psico-USF, v. 11, n. 1, p. 113-122, jan./jun. 2006 a migalhinhas. E outras, que é o meu caso, que se agarra a pequenas migalha.

Considerando que a sua finalidade foi ser mãe e esposa, Norma, assim como Rute, não sabia mais o que poderia realizar, colocando-se no lugar de menos-valia, lugar de mulheres que terão maiores chances de ter depressão. Com a depreciação de suas potencialidades, o adoecimento parece ser visto como algo muito provável na trajetória daquelas que, como ela, tiveram como foco a maternidade e o casamento na construção de seus projetos de vida. O outro grupo descrito seria o das mulheres que sofreriam menos por se dedicarem menos aos outros, priorizando seus desejos pessoais. Essas seriam mais saudáveis por ambicionarem outros objetivos.

Apesar das dificuldades que algumas participantes relacionam ao processo de envelhecimento, outras também procuram relativizar as mudanças ocorridas no corpo, com o desejo de se perceberem de uma forma mais positiva.

Eu gosto de falar sempre assim: 'É cinco ponto dois que eu vou fazer em outubro' [52 anos]. Mas... ih! A gente pega muita cacetada na vida, a gente 'güenta. 'Güienta que quando chega um ponto, não sei, parece que o organismo da gente não segura, né? Mas eu agora... eu tenho que segurar, porque eu tenho que me cuidar mais... mais que... A gente não é mais novinho. Tem que seguir, né? Mas tô bem. Tô maravilhosa (Dora).

O não ser mais nova, não ser mais jovem confirma que o corpo e as relações estão passando por mudanças. De acordo com Dora, é necessário desenvolver estratégias que possibilitem lidar com as perdas inevitáveis da maturidade. Com a perda da beleza física padronizada pela mídia, da saúde para o trabalho e do bem-estar econômico, perde-se também a ilusão da juventude de que há ainda muito tempo para modificar relações e projetos. Para isso, é preciso rever também as próprias prioridades, as quais, muitas vezes, foram deixadas em segundo plano:

Toda a vida en tive isso, de não me preocupar muito comigo. E agora... hoje às vezes eu tenho certas dificuldades por isso mesmo. (...) Agora eu tô procurando ver se preocupo mais. É porque eu não lembrava disso, sabe? (Graça).

Mas eu me preocupando demais com os outros, isso fez. com que eu ficasse com essa crise de nervo muito grande que viesse a causar a depressão. Mas... quer dizer, fiquei esses anos todos com esse problema, não ajudei ninguém $e$ 
ainda me adoeci. E não resolvi problema de ninguém. Foi isso que aconteceu (Helena).

Torna-se fundamental às mulheres na maturidade a elaboração de novas metas. Tendo priorizado durante décadas os desejos de seus familiares, é como se agora precisassem aprender a se preocupar consigo próprias. A falta de investimento no autocuidado evidenciada nas discussões grupais coloca em questão que necessitam lembrar de si. Provavelmente, a meta que fique mais em evidência seja não só se prepararem para a velhice, mas reavaliarem como estão se cuidando e valorizando.

De certa forma, a oportunidade de conhecer outras mulheres com histórias e queixas semelhantes propiciou às participantes um espaço de reflexão sobre as dificuldades cotidianas e, conseqüentemente, o autocuidado (Diniz \& Coelho, 2003; Mori, 2002). Observou-se que o grupo contribuiu para o questionamento de concepções sobre a depressão e os papéis que assumem em suas relações afetivas. Ao ouvirem a si próprias e às outras, configura-se a possibilidade de revisão e de enfrentamento de situações de vida por elas associadas ao adoecer.

Embora avaliar a modalidade de intervenção grupal não fosse a proposta deste estudo, pôde-se, ainda que de maneira exploratória, identificar benefícios desta atividade para a mulher nesse período de vida. Em razão da falta de um controle sobre as condições que cercam o quadro depressivo de cada uma das participantes - como o tempo de acompanhamento psiquiátrico, tipo e dosagem da medicação utilizada antes, durante e depois dos encontros, além da utilização de um grupo-controle para comparação dos resultados obtidos -, não há como se realizar uma avaliação mais precisa dos benefícios do grupo.

No entanto, de acordo com os dados apresentados na segunda aplicação do BDI, é possível que o trabalho tenha contribuído para a redução nos índices de depressão, o que aponta para a necessidade de estudos com um controle mais rigoroso. Foi observado que a redução nos índices foi maior entre as participantes que estavam apresentando o primeiro episódio depressivo, o que sugere igualmente a importância de se realizarem pesquisas que investiguem o grupo enquanto instrumento de intervenção precoce em casos de depressão em mulheres na maturidade. A partir dos depoimentos e dos resultados do BDI, aponta-se a intervenção psicológica grupal como uma modalidade de atendimento de valor inegável com o público em questão.

\section{Considerações finais}

O presente estudo teve como proposta ampliar o conhecimento sobre sintomas depressivos em mulheres na maturidade. Para isso, investigou-se a perspectiva de algumas mulheres sobre eventos desse período que podem ter contribuído para a sintomatologia. A queixa depressiva apresentada pela mulher parece ter articulações com a transição que está vivendo. Esta transição é marcada por estereótipos que refletem uma desvalorização do envelhecimento feminino. Num primeiro momento, a mulher vivenciou o crescimento dos seios, a menarca, etc. Agora, deparase com ondas de calor e irregularidades menstruais que influenciam seu humor. Os dois momentos representam, respectivamente, a entrada na juventude e a oficialização social do seu processo de envelhecimento. No entanto, se a jovem é exaltada, a mulher madura não recebe o mesmo crédito. $\mathrm{Na}$ rede pública de saúde, por exemplo, os serviços priorizam a mulher em idade fértil (Mori, 2002), indício do menor investimento financeiro e social voltado à mulher após o término da fase reprodutiva.

O sentimento de ter pela frente um tempo de disponibilidade, devido, por exemplo, ao crescimento dos filhos, pode deixar a mulher mais aberta a possibilidades de novos desejos em sua vida. Contudo, em nossa sociedade, este processo de ressignificação das relações interpessoais e de projetos pela mulher ainda tende a ser vivido com grande dificuldade, tendo em vista os mitos e preconceitos relacionados ao seu envelhecimento.

Idade, singularidade e sociedade: difícil convergência. Ao se perceber diferente do que era antes, a mulher não mais identifica em si aquela jovem que começava a descobrir sua própria sexualidade. Hoje, defronta-se com eventos estranhos num corpo até então aparentemente conhecido. Algumas se questionam sobre os projetos que podem realizar, como se o seu valor se restringisse a cuidar da família. Como exerceram o papel de cuidadora dos filhos e maridos durante anos, na maturidade sentem dificuldade em aprender a valorizar o autocuidado.

A pouca valorização que é concedida ao lugar social e à experiência da mulher que envelhece por vezes justifica seu receio de envelhecer, contribuindo para maior fragilização e adoecimento físico e psíquico. É preciso que se questione a construção cultural dos papéis tradicionalmente assumidos pelas mulheres, a fim de que seja revista esta limitação do destino biológico que lhe é imposto. Assim, provavelmente haverá maiores investimentos em ações dirigidas a esse 
público, que requer pesquisas e serviços de assistência específicos.

A análise realizada permite afirmar que o grupo é um rico instrumento a ser utilizado pelo psicólogo clínico em seu trabalho. Essa modalidade apresenta possibilidades que precisam ser mais bem exploradas por profissionais e pesquisadores. A ampliação da utilização de grupos na rede pública pode proporcionar a seus usuários, sobretudo os de baixa renda, além de um espaço de escuta, uma rede de suporte com a qual possam enfrentar as adversidades em comum. Indica-se, em especial, a utilização da modalidade grupal com pessoas que tenham queixas clínicas parecidas, como a depressão, tendo em vista que a homogeneidade dos integrantes contribui para que se fale das dificuldades pessoais com menor constrangimento, facilitando que cada membro ajude os demais a realizar uma revisão de concepções autodepreciativas, como no grupo em questão.

\section{Referências}

Appolinário, J. C. (2001). Envelhecimento e a saúde mental da mulher: menopausa e perimenopausa. Em Instituto de Psiquiatria da Universidade Federal do Rio de Janeiro. Cadernos IPUB, 10. Envelhecimento e Saúde Mental. 3.ed. Rio de Janeiro, RJ: UFRJ/IPUB, p. 141-148.

Ciornai, S. (1999). Da contracultura à menopausa: vivências e mitos da passagem. São Paulo, SP: Oficina de Textos.

Coelho, V. L. \& Diniz, G. (2005). Da solidão à solidariedade: grupos de familiares de idosos com demências. Em T. Féres-Carneiro (Org.). Casal $e$ familia: efeitos da contemporaneidade. Rio de Janeiro, RJ: Editora da PUC-Rio, p. 177-199.

Cunha, J. A. (2001). Manual da versão em português das Escalas Beck. São Paulo, SP: Casa do Psicólogo.

Diniz, G. \& Coelho, V. (2003). Mulher, família, identidade: a meia-idade e seus dilemas. Em T. FéresCarneiro (Org.). Família e casal: Arranjos e demandas contemporâneas. São Paulo, SP: Loyola, p. 79-96.
Goldfarb, D.C. (1998). Corpo, tempo e envelhecimento. São Paulo, SP: Casa do Psicólogo.

McGoldrick, M. (1995). As mulheres e o ciclo de vida familiar: Uma estrutura para a terapia familiar. Em B. Carter \& M. McGoldrick (Orgs.). As mudanças no ciclo de vida familiar. Porto Alegre, RS: Artes Médicas, p. 30-64.

Minayo, M. C. S. (1993). O desafio do conbecimento: Pesquisa qualitativa em Saúde. São Paulo, SP: HUCITECABRASCO.

Miranda, S. M. R. (1996). Tempo de Viver: Uma análise dos significados do climatério na mulher favelada (Dissertação de Mestrado). São Paulo: Pontifícia Universidade Católica de São Paulo.

Mori, M. E. (2002). A vida ouVida: a escuta psicológica e a saúde da mulher de meia-idade (Dissertação de Mestrado). Brasília: Universidade de Brasília.

Organização Mundial de Saúde (1994). Classificação de Transtornos Mentais e de Comportamento da CID-10: descrições clinicas e diretrizes diagnósticas. Porto Alegre, RS: Artes Médicas.

Py, L. (2004). Envelhecimento e subjetividade. Em L. Py, J. L. Pacheco, J. L. M. Sá \& S. Goldman. (Orgs.). Tempo de envelhecer: percursos e dimensões psicossociais. Rio de Janeiro, RJ: Nau, p. 109-136.

Ramos, D. (1998). Viva a menopausa naturalmente. São Paulo, SP: Augustus.

Sánchez, M. \& Roel, I. (2001). El proceso de envejecimiento en la mujer. Revista Tiempo: El portal de la Psicogerentología, 8. Disponível em: <http://www.psicomundo.com/tiempo/>. Acessado em: 30/12/2005.

Recebido em julho de 2005 Reformulado em janeiro de 2006 Aprovado em fevereiro de 2006

Sobre as autoras:

Isalena Santos Carvalho é psicóloga clínica, especialista em Saúde Mental (UFRJ), mestre (área Psicologia Clínica) e doutoranda em Psicologia pela Universidade de Brasília (UnB). Atualmente, desenvolve trabalhos de pesquisa e intervenção psicológicas nas cidades de São Luís (MA) e Brasília (DF).

Vera Lúcia Decnop Coelho é psicóloga clínica e doutora em Psicologia. É aposentada da UnB e pesquisadora associada adjunta do Instituto de Psicologia, UnB. Vem se dedicando ao estudo da meia-idade e da velhice. É 
membro da equipe multidisciplinar do "Centro de Medicina do Idoso" do Hospital Universitário da UnB, onde desenvolve atividades de ensino, pesquisa e assistência a idosos com demências e familiares. 